\title{
Principles for Enhancing Earth System Governance and Sustainable Development Through Informality
}

Dumisani Chirambo, Seeds of Opportunity, Malawi

(iD) https://orcid.org/0000-0003-2310-9896

\section{ABSTRACT}

Even though the United Nations Framework Convention on Climate Change introduced the Nationally Determined Contributions (NDCs) framework as a novel mechanism for improving climate change governance and promoting sustainable development, some studies show that NDCs are still far from achieving the $2{ }^{\circ} \mathrm{C}$ target. Non-state actors from the informal economy can potentially improve the implementation of the NDCs framework and Sustainable Development Goals framework as much of the urban population growth occurring in developing nations is taking place in slums/informal settlements. This paper is therefore an inductive inquiry to address knowledge gaps on how non-state actors can augment Earth System Governance and NDC implementation in the context of Global South cities. The paper highlights that Earth System Governance and climate change adaptation may be improved by increasing the use of South-South Climate Finance mechanisms in urban adaptation programmes and to facilitate institutional reforms that can lead to substantial increases in domestic tax collection.

\section{KEYWORDS}

Environmental Governance, Nationally Determined Contributions (NDCs), South-South Climate Finance, Sustainable Development Goals (SDGs), Urbanisation

\section{INTRODUCTION}

Climate change is a global development and global governance challenge as it is a collective action problem whose remedy is beyond the reach of any singular actor or country (Brechin, 2016). Furthermore, improving climate change governance has 
proven to be challenging due to the long time-scale over which the changes occur, the possible need for action well before the magnitude (and certainty) of the impacts is clear, the intrinsic global scale of climate change, and that action at the regional scale has limited prospects for ameliorating regional-scale impacts (Field et al., 2007). With respect to global development, climate change impacts have been shown to have the potential to make the Sustainable Development Goals (SDGs) unattainable in certain regions of the world by reinforcing inequalities and poverty and/or creating new forms of inequality and poverty (Nagoda, 2015; Wong, 2016). Additionally, recovery from climatic shocks is often slow and more so slower for the poor than for the non-poor. Reference can be made to the cases of Ethiopia and Tanzania where studies have shown that after the 1984 - 85 famine in Ethiopia, rural households took ten years, on average, to rebuild livestock holdings to the levels existing before the famine, and households affected by drought in Ethiopia and the United Republic of Tanzania had lower incomes than unaffected households even ten years later (FAO, 2015; Hallegatte et al., 2016). Consequently, it might be argued that efforts to alleviate poverty and promote sustainable development could prove to be futile if the global development and climate change governance architecture does not provide new innovations and policies that can reduce climate change vulnerability.

The United Nations Framework Convention on Climate Change (UNFCCC) introduced the Nationally Determined Contributions (NDCs) framework as a novel mechanism for improving climate change governance and promoting sustainable development (Levin et al., 2015; Mbeva et al., 2015). Through NDCs, both developed and developing countries are anticipated to state their ambitious climate change mitigation, adaptation and financing commitments in a bid to ensure that global temperatures reach the goals in the Paris Agreement and the global goal to limit temperature increase to $2^{\circ} \mathrm{C}$ above pre-industrial levels (Hood et al., 2015). However, the NDCs are still far from achieving a collective plan to keep the global temperature increase to well below $2{ }^{\circ} \mathrm{C}$ and as such the world is also at risk of being caught in a cycle of low and uneven growth and, with it, of failing to reach the SDGs to eliminate poverty and provide a better life for all (Bak et al., 2017). Moreover, another drawback in the climate change policy domain is that many climate change policies emphasise the management of climate induced physical hazards such as floods, droughts and storms with little consideration of other factors that increase climate risk such as poverty rates, demographic characteristics, and governance structures (Barrett, 2014). Consequently, the Earth System Governance Project suggested that creating a climate compatible inclusive future will require the development of policies and development models that promote substantial transformations of existing socio-economic practices within today's societies in-order to eliminate the prioritisation of dominant economic and political interests (Boyd et al., 2014).

Some current research on climate change governance and environmental resources governance in the Global South include van Asselt (2016) who looked at the roles that non-state actors can play in improving the implementation of the Paris Agreement. Van Asselt (2016) concluded that regardless of many 
non-state actors not having a formal role in the UNFCCC process, non-state actors can support the implementation of the Paris Agreement by playing an essential role in holding national governments accountable for meeting their commitments, and putting pressure on them to raise their ambition. Birkmann et al. (2014) looked at new challenges for urban and spatial governance and concluded that increasing attention has recently been focused on the necessity to adapt urban infrastructure in exposed cities, but much less attention has been given to institutional dimensions of adaptation in the field of urban planning and risk management. Maupin (2017) explored climate change policies in Africa and discussed opportunities to address climate change and development challenges concurrently. Maupin (2017) concluded that Africa fails to pursue green development pathways since multi-levelled interactions between climate change policies and development-centred policies are disintegrated. Chu et al. (2016) looked at how cities may promote public participation and facilitate the engagement of different civil society actors in climate adaptation planning; and they concluded that an emphasis on building multi-sector governance institutions that ensure tight and multilevel relationships between government and civil society actors can ensure that diverse civil society actors have an ongoing voice in adaptation planning and implementation. Regardless of these studies, knowledge gaps still exist regarding the various roles to which different nonstate actors can pursue in-order to enhance Earth System Governance and NDCs implementation in the context of Global South cities. Consequently, through an inductive inquiry based on various research articles, academic literature, policy briefs, and project reports, this paper therefore attempts to highlight and add to the existing knowledge on Earth System Governance the policies, actions and strategies that local government policy makers and informal sector actors can pursue in-order to enhance Earth System Governance and the implementation of the SDGs and NDCs in the Global South. The paper is arranged as follows: Section 2 describes the methodology used in the paper. Section 3 provides an analysis of factors that can enable NDCs to simultaneously reduce inequality and enhance Earth System Governance. In Section 4, strategies to facilitate the successful implementation of SDG 11 (Sustainable Cities) using South-South Climate Finance (SSCF) and the Informal Sector are provided. The roles for nonstate actors in supporting the implementation of the SDGs and NDCs is provided in Section 5. A discussion focusing on how SSCF might be leveraged to improve the domestic mobilisation of taxes and non-traditional development finance to support Earth System Governance in the Global South is provided in Section 6. Finally, the conclusion in Section 7 concurs with other studies on Earth System Governance by emphasising how the economic and political interests of city governments need to be transformed so that actors from the informal sector can be empowered to undertake activities related to conserving urban ecosystems and enhancing climate change resilience. 


\section{MATERIALS AND METHODS}

In-order to achieve the aim of this paper, an inductive inquiry using secondary data consisting of various research articles, academic literature, policy briefs, and project reports focusing on the nexus of climate finance, urban poverty and environmental governance was undertaken. Since the research was inductive in nature, the literature used in the research were chosen through purposive sampling whereby the paper's keywords and other prominent words such as Africa, climate change adaptation, vulnerability and climate finance were used in different combinations as search words in the Google Scholar search engine. The results were also refined to show literature published since 2014 only. Additional documents and literature included in the analyses were obtained from the data that was used in the author's previous publications. Since there are substantial variations in the way that NDCs are presented and the coverage of issues in NDCs, the paper did not attempt to create a methodological framework to aid in the analysis of data. Instead, the analysis in the paper focuses on highlighting the areas to which there is fragmented or limited understanding of how the climate finance, urban poverty and environmental governance nexus impacts Earth System Governance and discussing their post-2015 relevance. The methodological approach taken in this paper is therefore similar to other studies that were also significantly based on secondary data such as Asongu (2016) who undertook a literature review in-order to argue how foreign aid could lead to more sustainable development outcomes; Kuyper et al. (2018) who undertook a literature review in-order to outline the multifaceted roles played by non-state actors within the UNFCCC; Ford et al. (2015) who did a systematic review of peer-reviewed papers, grey literature and policy documents to document and characterise climate change adaptation initiatives; and Mayrhofer and Gupta (2016) who undertook a literature review approach on the nature, evolution, strengths and limits of the co-benefits approach in relation to climate change.

\section{NDCS AS A NEW INNOVATION FOR REDUCING INEQUALITY AND ENHANCING EARTH SYSTEM GOVERNANCE}

The Paris Agreement and NDCs framework may be considered as the new international climate change regime that will completely succeed the Kyoto Protocol from 2020. Unlike the Kyoto Protocol which tried to impose legally binding emission reduction targets for certain countries, the framework for the Paris Agreement is novel in that it is based on countries developing NDCs as overarching national climate change policies to support global "ambitious voluntary commitments" on climate change mitigation, adaptation, finance, technology transfer and capacity building. Since the NDCs have failed to reach the $2^{\circ} \mathrm{C}$ target, many studies have focused on determining the policies and strategies that can be implemented to ratchet-up mitigation actions to subsequently reach the $2^{\circ} \mathrm{C}$ target (Antwi-Agyei et al., 2018; Jiang and Hanaoka, 2017). Arguably, such an emphasis on ratcheting-up mitigation efforts in NDCs may be detrimental 
as it might mask the opportunities to use NDCs to reduce inequalities and enhance Earth System Governance particularly since developing countries in Africa have low greenhouse gas emission levels and as such would be more incentivised to act on their NDC pledges due to their potential impact to promote sustainable development rather than for solely climate change mitigation reasons.

In the status quo, it is generally agreed that the countries or communities that will be the most adversely affected by climate change are the countries that contributed the least to the cumulative global greenhouse gas emissions and are the countries with the least capacity to adapt (Barrett, 2013). Whilst most studies emphasise that developing countries particularly in Africa are the most vulnerable to climate change (Barrett, 2013; Maupin, 2017), there are now emerging signs that within such developing countries the levels to which communities are adversely affected by climate change also varies widely and that disproportionately less adaptation finance arrives in the areas of highest need (Barrett, 2014). This therefore suggests that countries and regions that are more vulnerable to climate change are provided with proportionately fewer funds to address their climate risks and as such they also have the least resources to reduce climate change induced inequalities.

Similarly, the need to reduce inequalities in their many forms within and across countries is imperative for the SDGs to be attained, and also to limit pollution and the overexploitation of natural resources. Accordingly, out of the 17 SDGs, 11 address forms of inequality, in terms of equality, equity and/or inclusion (Goals $1,3,4,5,6,7,8,9,10,11,16$ and 17), and SDG 10 explicitly proposes reducing various forms of inequalities. Aspects related to reducing inequality include a diverse range of issues such as wealth and income inequalities to regulating global financial markets and the question of power imbalances in global governance (Freistein and Mahlert, 2016). However, whilst the implementation of the NDCs and SDGs have the potential to create synergies to promote inclusive growth and generate mutual benefits through the integration of various SDGs and NDCs policies and measures, there are concerns that since the Paris Agreement and SDGs were each negotiated and adopted through separate international processes and forums, their implementation will also be undertaken via separate financial and institutional frameworks (Northrop et al., 2016). Arguably, it might be envisaged that at the implementation stage there could be challenges in building positive synergies among climate change and sustainable development agendas. It should therefore not be assumed that the countries that have adopted both the Paris Agreement and SDGs framework to be experiencing accelerated progress towards enhanced climate change resilience and sustainable development since these two frameworks can be operating in different silos at national level and also be targeting the wrong beneficiaries. Arguably, to limit this scenario, there could be merit in explicitly incorporating how NDCs will be targeting inequality since inequality is a prominent issue in the SDGs framework but it is not always well articulated or not well integrated with many climate change interventions. 


\section{AUGMENTING THE IMPLEMENTATION OF SDG 11 THROUGH SOUTH-SOUTH CLIMATE FINANCE (SSCF)}

Different criteria may be used to describe the differences between developed countries and developing countries. For example, Suberu et al. (2013) considers the level of access to electricity as a criteria in differentiating developing countries from developed countries since developed countries have universal access to electricity whilst developing countries are struggling to attain universal access to electricity (i.e. the electricity access rate for Africa is $43 \%$ and for developing countries is 76\%) (Hancock, 2015). Another criteria that may arguably be used to differentiate developing countries from developed countries could be their levels of informality. Accordingly, 54\% of all employment in Africa emanates from the informal economy in comparison to only $3 \%$ of employment being in the informal economy in Highly Industrialized Countries (Obeng-Odoom, 2011). Additionally, in developing countries many cities have $30 \%-50 \%$ of their population living in informal settlements and in almost all developing nations more than half the urban workforce work is in informal employment (i.e. South Asia at $82 \%$ in informal employment and sub-Saharan Africa (SSA) at 66\%) (Satterthwaite et al., 2018). With the aforementioned factors in mind, some commentators such as Urban (2018), van Gevelt et al. (2018) and Urpelainen (2012) have therefore suggested that since the socio-economic contexts of developing and developed countries have wide disparities, and because some of the major challenges of developing countries do not exist in developed countries there is a likelihood that duplicating the development paradigms and infrastructure models of developed countries in developing countries will not be sufficient to meet the needs of developing countries. Similarly, other commentators have argued that new modes of global cooperation and governance such as South-South Climate Cooperation (SSCC) modalities, which have now been consolidated in the NDCs, should be promoted since such approaches may have more potential to foster pro-poor innovation for developing countries than traditional North-South approaches that are typically rooted in the innovation priorities of developed countries (Tawney et al., 2015). Arguably, this can also mean that developed country policies that have been successful in enhancing the governance of earth systems in developed countries may not necessarily be successful in improving the governance of earth systems when they are transposed in a developing country context. Consequently, the most effective climate change policies that can also enhance the governance of earth systems in developing countries could be the ones that are developed through SSCC modalities.

One of the areas with significant scope for which SSCC modalities and SSCC policy development can augment in-order to facilitate sustainable development is in the implementation of SDG 11 (i.e. create sustainable cities). Some projections indicate that by 2050 global urban population will exceed 6.7 billion and that nearly $80 \%$ of population growth will take place in low and middle income countries, where populations are already rising by over one million people per week (C40, 2016), meaning that by 2050 there will be 2.1 billion more people living in Asian and African 
cities (Barnard, 2015). Unfortunately, even new town building as an urbanisation strategy in Africa has proven to be ineffective as both old and new cities in Africa are exhibiting signs of being unable to address contemporary urban challenges such as rapid urbanisation, informality, social exclusion, urban sustainability, climate change and environmental degradation (Kiunsi, 2013; Abubakar and Doan, 2017). Moreover, with the increase in climate risks, one of the greatest challenges for climate change adaptation is how to build resilience for the millions of urban dwellers who are estimated to live in informal settlements (Satterthwaite et al., 2018). For example, between 1990 and 2014 rapid migration to cities and corresponding increases in the global urban population led to the actual number of people living in slums to increase from 689 million to 881 million (UN, 2018a). Additionally, the achievement of SDG 11 is facing significant challenges as unplanned and rapid urbanisation, poor land management, and non-risk informed policies and investments are posing as the underlying risk drivers of disaster mortality. Accordingly, from 1990 to 2013, almost $90 \%$ of mortality attributed to internationally reported disasters occurred in low and middle-income countries, many of which have seen rapid urban expansion in recent years (UN, 2018a).

According to the Intergovernmental Panel on Climate Change (IPCC), the successful leveraging of climate finance is paramount to achieving SDG 11 (Revi et al., 2014). This follows that even though many of the significant emerging global climate risks are concentrated in urban areas, and urban climate change-related risks are increasing with widespread negative impacts on people (and their health, livelihoods, and assets) and on local and national economies and ecosystems, urban centres around the world face severe constraints to raising and allocating resources to implement climate change adaptation programmes and international financial institutions provide limited financial support for adaptation in urban areas (Revi et al., 2014). Similarly, there is a lack of innovative instruments to allow bilateral and multilateral development institutions and Development Finance Institutions to leverage climate finance and scale-up investments in climate change programmes (Abramskiehn et al., 2017). These issues therefore suggest that there is an absence of specific investment and financing channels that can augment urban environmental governance and climate change resilience. On the other hand, the global allocation of climate funds in 2015 and 2016 stood at around US\$409 billion/year whereby mitigation activities accounted for an average of $93 \%$ of these climate finance flows, and $74 \%$ of all mitigation actions were devoted to renewable energy generation (Buchner et al., 2017). Additionally, during 2015 and 2016 approximately US\$8 billion of climate finance flowed between different developing countries as SSCF (Buchner et al., 2017), and the share of Foreign Direct Investment (FDI) originating from developing countries has increased substantially from $8 \%$ of total FDI flows in 2000 to almost 26\% in 2015 (Gold et al., 2017). These aspects mean that multinationals from developing countries invested around US\$378 billion abroad in the year 2015, with much of this investment being between developing countries as South-South FDI (Gold et al., 2017). However, bearing in mind that most climate finance is channelled towards the renewable energy sector, it could be 
argued that there could be a threat that SSCF could also have an undue bias towards the development of renewable energy financing models and mechanisms rather than focusing on developing novel urban adaptation financing models and mechanisms. Consequently, a factor contributing to the vulnerability of urban dwellers in developing countries and a contributing factor to failures in some urban climate change adaptation measures could be that there is a lack of appropriate financial mechanisms addressing the needs and vulnerabilities of urban dwellers and their non-state actors. Therefore, improving environmental governance systems to enable the attainment of SDG 11 in cities might be feasible once SSCC innovation systems and SSCF modalities become more aligned towards creating bespoke Global South climate finance modalities that also encompass measures to improve the livelihoods of urban dwellers especially those in informal settlements.

\section{AUGMENTING SDGS AND NDCS IMPLEMENTATION THROUGH NON-STATE ACTORS}

Local government structures and city governments are often the closest entities for planning and implementing adaptation strategies suitable for the particular geographic and social context in which they are located (Pasquini et al., 2013). However, in many developing countries various factors have made it problematic for city governments to implement climate change policies that maintain or enhance livelihoods and ecosystems. For example, an analysis by Ojha et al. (2016) showed that climate change vulnerability and environmental degradation is engendered due to the climate change discourse still being dominated by a science that focuses on vulnerability as an outcome of biophysical climate change and the risks of natural hazards, rather than framing vulnerability as an outcome of the interaction between the impacts of natural hazards and existing social, political, governance and environmental factors. Additionally, a significant number of existing climate models are not downscaled to the city level (Revi et al., 2014) meaning that there is a high probability that many local governance structures for cities in many developing countries use inaccurate data for their climate change planning and policy formulation.

Similarly, in many climate change policies, biophysical climate change and the risks of natural hazards are a major consideration and as such there is a great emphasis in trying to address climate change vulnerability through technological innovations and infrastructure development. However, whilst innovation is essential for addressing climate change, some commentators emphasise that technological innovation alone is insufficient to address climate change challenges, and as such climate change policies need to consider the use of bottom-up social innovation or non-technical innovation. This follows that bottom-up social innovation or non-technical innovation incorporate behaviour and lifestyle changes and new business models and governance systems that can empower less powerful actors thereby leading to new opportunities for various actors to develop new strategies for enhancing climate change resilience and environmental governance (Bergman et al., 2010). Arguably, since there are few 
studies on climate change adaptation in the Global South urban context, and with social innovation becoming a new phenomenon in the urban governance field, researchers and practitioners need to shed more light on which areas and city contexts social innovation can be applied to enhance Earth System Governance.

Local governments, similar to national governments can be expected to face financial strain in their efforts to mobilise financial resources for the implementation of climate change policies. Arguably, the level of funding needed for sound urban adaptation could exceed the capacities of local and national governments and international agencies (Revi et al., 2014; UNEP, 2016). For example, some local governments rely almost exclusively on central government transfers for implementation of public services, and this limits their degree of freedom to innovate or modify business-as-usual practices and incorporate climate change measures (Bird et al., 2016). The question then becomes how can the limited available resources for local governments and local non-state actors be maximised to have a significant positive impact on Earth System Governance? Research by Clark et al. (2018) highlighted that there are disconnects between global ambitions (on climate change and sustainable development) and the actual (political, financial and governance) realities, and as such the mechanisms by which global ambitions can be fulfilled will likely require transformations across policies, economies, mindsets, approaches and accountabilities. For example, an analysis by Pasquini et al. (2013) focusing on the constraints to climate change adaptation in eight municipalities in the Western Cape Province of South Africa showed that whilst South Africa is a party to many global environmental treaties and conventions, the reality at local level is that climate change policies fail to be mainstreamed or implemented. In this case, constraints to effective climate change policy implementation at local level were noted to be individual-level barriers (such as a lack of understanding of climate change and adaptation options) to regulatory/institutional barriers (such as the problems posed by party politics) to socio-cultural barriers (such as a lack of interest within municipal constituencies for climate change issues). Additionally, Nightingale (2017) highlighted that resource governance struggles often have little to do with the resources themselves but are usually about power and politics hence climate change policy outcomes are profoundly shaped by struggles for authority and recognition rather than technical issues. Arguably, with these considerations in mind, improving the implementation of city climate change policies in the Global South will therefore call for a need to assess policy failures and services provision from a different perspective.

In essence, the roles of city governments in protecting the environment and reducing climate change vulnerability usually falls within the remit of providing local infrastructure and public services, promulgation and regulation of land use and building codes, etc. However, many city governments fail to effectively manage climate and environmental risks in their jurisdictions since the majority of urban inhabitants in Global South cities are noted to live in informal settlements that are characterised by houses and apartment blocks that have bypassed planning and building regulations, and in areas with minimal bulk infrastructure and public services, such as waste collection and management, public transport, clean piped water, health 
facilities, recreation and other amenities (Taylor and Peter, 2014). On the other hand, Climate Compatible Development (CCD) is defined as development that minimises the harm caused by climate impacts while maximising the many human development opportunities presented by a low emissions, more resilient future (Stringer et al., 2014). This therefore means that the creation of new partnerships between divergent stakeholders to address emerging urban environmental governance challenges and the creation of new employment opportunities in communities through measures aimed at reducing climate risks can all be included as part of a CCD paradigm. An analysis by Chirambo (2019), Schwartz et al. (2004) and Santos (2003) showed that in conflict, post-conflict and buffer circumstances, entrepreneurs, small enterprises or small-scale private service providers often play a key role in providing essential services, including financial services through microfinance, in the absence of fullyfunctioning governments, established public utilities and major private investments. It can be therefore be argued that other non-state actors such as informal businesses, Small, Medium and Micro Enterprises (SMME) and Small and Medium Enterprises (SMEs) can equally support or replace city governments in undertaking their duties related to the provision of some services once they are accorded the mandate to do so as the case is in conflict, post-conflict and buffer circumstances. Furthermore, by recognising and giving service provision mandates to SMME and SMEs to facilitate livelihood enhancements and community resilience building which in turn improves the governance and utilisation of local environmental resources by local actors, it could be argued that a CCD strategy has been enacted since new jobs for local people will be created in communities and these would also reduce their vulnerability to various socio-economic shocks. However, in-order for such strategies and actions to be successfully executed, there will be a need for local governments to develop Local Empowerment Plans that can mandate and coordinate the duties or roles that various SMME and SMEs will be undertaking especially in informal settlements. Furthermore, Corporate Social Responsibility (CSR) activities from the private sector can provide significant financial resources for community projects (e.g. CSR activities mobilise up to 250 billion Rupees (US\$3.89 billion) a year in India (Balch, 2016)), and African migrants can provide US $\$ 50$ billion in diaspora savings that could be leveraged for low-cost project finance (Chirambo, 2017). This therefore means that additional funds to actualise these Local Empowerment Plans could be mobilised through CSR modalities and remittances, whereby private companies and migrants can as part of their CSR activities and motivation to alleviate poverty in its many dimensions help establish city level revolving funds, innovation funds or similar instruments that can pool in new forms of climate finance to directly help social SMMEs and social SMEs to undertake these new mandates.

\section{DISCUSSION}

Due to the significant presence of informality, SMMEs and SMEs in developing countries, there is a great potential that informal businesses, SMMEs and SMEs 
can become effective non-state actors that can support local governments where they have inadequacies in providing services that can improve the livelihoods of urban communities including those in informal settlements. Improved environmental governance and climate change governance in developing countries can therefore hinge upon the levels of support that is provided to informal businesses, SMMEs and SMEs to enable them to adapt to their climate risks and opportunities. According to Crick et al. (2017), SMMEs and SMEs generally depict two forms of adaptation practices, namely reactive coping mechanisms and sustainable adaptation responses. In the case of reactive coping mechanisms, business is scaled back as SMMEs and SMEs sale assets due to distress whilst in the case of sustainable adaptation responses, business operations are maintained at existing levels as SMMEs and SMEs change their product mix (Crick et al. (2017). Therefore, efforts should be made to facilitate sustainable adaptation responses since these have the greatest potential to enable businesses to provide services and jobs in the communities whilst also empowering community members to take active roles in enhancing their livelihoods. Notably, financial barriers are a key reason why firms resort to reactive coping mechanisms, while general business support, and access to information, technology and adaptation assistance encourages sustainable adaptation responses (Crick et al., 2017). Unfortunately, since climate finance levels to Africa and other developing regions are far from satisfactory in terms of the size, source and distribution (Yu, 2014; Adenle et al., 2017) meaning that the provision of sufficient and predictable levels of climate finance to increase climate change adaptation and technology transfer programmes in developing countries continues to be challenging, it could be argued that the potential to which informal businesses, SMMEs and SMEs can ultimately have in enhancing the governance of earth systems in an urban context will be diminished unless policies and incentives to increase the mobilisation of climate finance become more effective and new financial mechanism to support informal businesses, SMMEs and SMEs are actualised.

An assessment of what successful transitions towards enhanced climate change adaptation and enhanced Earth System Governance might entail shows that there will be a need to increase climate funds for urban areas since the current adaptation costs are likely to be at-least 2 to 3 times higher than international public finance for adaptation, and to meet finance needs and avoid an adaptation gap, the total finance for adaptation in 2030 would have to be approximately 6 to 13 times greater than international public finance today (UNEP, 2016). Moreover, the cost of adaptation are now five times higher than previous estimates suggesting that the cost of adaptation in Africa may rise above US $\$ 100$ billion per year by 2050 and that while adaptation finance through the UNFCCC will help offset some of these costs, it is not of the magnitude required for climate proofing (Adenle et al., 2017). On the other hand, there is some recognition that developing countries can reduce these adaptation finance gaps and the impact of aid volatility by initiating policies to drive reforms and provide incentives to steer investment to priority needs, and increase the mobilisation of domestic taxes to ensure the equitable delivery of adaptation programmes at national and urban levels (Revi et al., 2014). However, efforts to increase climate finance and development finance 
through domestic sources have not been very encouraging. For example, the rate of taxation (ratio of tax revenue to Gross Domestic Product (GDP)) in Least Developed Countries (LDCs) declined from the peak of $11.1 \%$ in 2012 to $8.8 \%$ in 2016 and for SSA countries there was a decline from $14.9 \%$ in 2006 to $10.7 \%$ in 2016, showing that the regions most in need of resources still face challenges collecting taxes and revenues for development programmes (UN, 2018a). Additionally, remittances sent by international migrants to low- and middle-income countries reached US\$466 billion in 2017, more than three times the amount of Official Development Assistance (ODA) they received that year (UN, 2018b), but overall remittance flows have declined as globally total remittances sent have declined to US\$538 billion ( $0.72 \%$ of global GDP) in 2016 from US\$555 billion in 2015 (UN, 2018a). Moreover, should the United States of America continue with its plans to withdrawal from the Paris Agreement, up to US $\$ 2$ billion, or $20 \%$ of pledged finance to the Green Climate Fund (GCF) to support climate resilient growth in the Global South will become unavailable (Buchner et al., 2017). Similarly, in 2017, net ODA from member countries of the Development Assistance Committee (DAC) of the Organisation for Economic Co-operation and Development (OECD) totalled US\$146.6 billion, a decrease of $0.6 \%$ from 2016 level in real terms (UN, 2018a). Arguably, even though there are increasing financial demands to ensure the development of sustainable cities and to counter the effects of climate change, population growth, and rapid urbanisation, the domestic tax systems and global financial systems are not yet raising revenues that are commensurate with the required financial demands and climate change challenges. This arguably provides opportunities for SSCC innovation systems and SSCF modalities to integrate capacity building and policy reforms to enhance the collection of domestic taxes and revenues as a priority intervention area.

An assessment by Sireh-Jallow (2017) showed that the domestic mobilisation of development finance in Africa is lagging because African policymakers do not always utilise all the divergent forms of non-traditional development finance options (e.g. diaspora bonds, carbon sequestration and trading, etc.) that are available for them to leverage with ODA. A factor that was identified as a constraint to the adoption of nontraditional development finance was highlighted as the need for upfront expenditures by governments in-order to create the environment for more fiscal space in the medium to long term (Sireh-Jallow, 2017). This therefore means that there is a paradox in that if governments spent some of their resources on capacity building and policy reforms to create conducive environments for non-traditional development finance mechanisms to thrive, the countries would be able to completely or partly address their climate and development financing gaps, yet the available resources are spent on reinforcing the status quo by depending on unreformed/archaic financial markets and development aid paradigms that engender local and international development finance gaps. Since there is a need to initiate transformations across policies, mindsets and approaches (Clark et al., 2018) to facilitate improved Earth System Governance and sustainable development, there could be justification in using SSCC innovation systems and SSCF as a new source of "additional" finances that can be used to 
implement activities focusing on reducing the constraints that governments have in initiating the reforms and policies that can create conducive environments to promote the utilisation of non-traditional development finance mechanisms. For example, the global allocation of climate funds in 2015 and 2016 for SSA was US\$12 billion and Middle East and North Africa received US\$8 billion (Buchner et al., 2017); during 2015 and 2016 approximately US\$8 billion of climate finance flowed between different developing countries (Buchner et al., 2017), and China's INDC incorporates a pledge to provide US\$3.1 billion (CNY20 billion) to establish the China South-South Climate Cooperation Fund for Climate Change, which is in addition to more than US\$2 billion that was already pledged for South-South Cooperation and climate-related activities before 2015 (Weigel, 2016; NDRC, 2015). As already highlighted, most climate change projects and policies have an emphasis on facilitating adjustments to physical climate change (e.g. dyke construction, retrofitting of buildings, or installing flood warning systems) with less emphasis on institutional aspects and administrative transformation processes to shift the models for running economies (Birkmann et al., 2014). It might therefore be envisaged that a significant amount of these climate finance flows go towards building or reinforcing physical structures, transport systems and hard infrastructure rather than using parts of the climate finance to improve the soft infrastructure (i.e. changes in the governance of institutions and policies, capacity building, and strategy development) or initiate institutional reforms, which commentators such as Buurman and Babovic (2016) and Bokpin (2017) consider to have a significant bearing on reducing the risks that individuals and societies face from extreme weather events and other climate and weather related impacts. In the context of this paper, the soft infrastructure and institutional reforms could have a particular emphasis on creating an enabling environment for improved domestic tax and resources mobilisation. With the aforementioned factors in mind, it is therefore conceivable that one of the greatest values to which SSCF and SSCC could have would be to provide additional financial and technical resources to enable Global South countries (and African countries in particular) to implement reforms that can enable the countries to be able to mobilise more domestic resources for socio-economic development. Ultimately, with more funds being available in Global South countries, non-state actors in both formal and informal economies in Global South countries will be able to have sufficient access to funds to enable them to enact programmes and projects that can enhance the governance of environmental resources and earth systems.

\section{CONCLUSION}

The Paris Agreement, NDCs and SDGs have aspirations and targets related to reducing the vulnerability of developed and developing countries to climate shocks and other socio-economic shocks. However, the global financial systems and governance systems for ensuring that financial and technical resources reach and support climate vulnerable communities have been shown to be in need of substantial transformations, especially when considering the ambitions of SDG 11 and SDG 13. Consequently, 
enhancing the governance of earth systems and promoting inclusive growth remains a challenge in both the international domain and local urban contexts. In this paper, it was emphasised that cities in developing countries are experiencing high rates of urbanisation and population growth more particularly in informal settlements where poverty and climate change vulnerability is also increasing. However, it was noted that within the informal sector there are informal businesses, SMMEs and SMEs that have the potential to complement or replace public utilities, local governments and major private investments to provide essential services and resilient infrastructure that could potentially reduce the vulnerability of communities to climate change. Additionally, it was highlighted that some of the development finance and climate finance gaps are not necessarily due to a lack of resources and finances but could be attributed to the failure of State actors to initiate substantive transformations in tax systems that could lead to increases in domestic tax mobilisation. Consequently, it may be argued that SSCF, being a new, emerging and non-traditional source of "additional" financial and technical resources for climate change programming and policy formulation has the scope to focus on correcting the pitfalls and shortfalls of global financial systems and governance systems since their governance structures are less engrained in past traditions.

Some studies on Earth System Governance emphasise that governments, individuals and non-state actors need to consider eliminating the prioritisation of dominant economic and political interests in-order to simultaneously foster social justice and institutional effectiveness when trying to achieve sustainable development and enhance the governance mechanisms for regulating the natural environment and ecosystems. The insights from this investigation concur with such studies and additionally suggest that city governments need to de-prioritise their political interests by considering providing mandates to actors in the informal sector so that their contributions to livelihood enhancement can now also be formally incorporated in climate change policies and local planning strategies to facilitate the achievement of SDG 11. More importantly, since Global South countries will have to develop their own unique policies and development paradigms that are different from Global North country policies in-order to enhance environmental governance and reduce mortality from climatic disasters, there could be some justifications in transferring some accountabilities and promoting the empowerment of less powerful actors in the informal sector so that the infrastructural, technological and social dimensions for enhancing the governance of natural resources and ecosystems in urban contexts are undertaken simultaneously. Such changes in approaches and policy directions can then ultimately lead to broader changes to outdated governance structures that restrict some non-state actors from being formally recognised in urban development policies. Once these changes are enacted it can therefore mean that the potential for transforming climate change challenges into opportunities for creating sustainable and inclusive societies and sources for asset building for vulnerable communities in the Global South can now slowly become a reality. 


\section{ACKNOWLEDGMENT}

An abridged version of this paper was presented at the 2018 Utrecht Conference on Earth System Governance. The author is thankful to the organisers of the 2018 Utrecht Conference on Earth System Governance for providing a platform for this research to be disseminated.

\section{FUNDING AGENCY}

Open Access Funding for this article has been provided by IGI Global. 


\section{REFERENCES}

C40. (2016). New Perspectives on Climate Finance for Cities: Finance Solutions for New and Emerging Infrastructure Approaches to Urban Climate Mitigation and Adaptation. C40 Cities Climate Leadership Group.

Abramskiehn, D., Hallmeyer, K., Trabacchi, C., Escalante, D., Netto, M., Cabrera, M., \& Vasa, A. (2017). Supporting National Development Banks to Drive Investment in Nationally Determined Contributions of Brazil, Mexico and Chile. Inter-American Development Bank.

Abubakar, I. R., \& Doan, P. L. (2017). Building New Capital Cities in Africa: Lessons for New Satellite Towns in Developing Countries. African Studies, 76(4), 546-565.

Adenle, A. A., Ford, J. D., Morton, J., Twomlow, S., Alverson, K., Cattaneo, A., Cervigni, R., Kurukulasuriya, P., Huq, S., Helfgott, A., \& Ebinger, J. O. (2017). Managing Climate Change Risks in Africa - A Global Perspective. Ecological Economics, 141, 190-201.

Antwi-Agyei, P., Dougill, A. J., Agyekum, T. P., \& Stringer, L. C. (2018). Alignment between nationally determined contributions and the sustainable development goals for West Africa. Climate Policy, 18(10), 1296-1312.

Asongu, S. (2016). Reinventing Foreign Aid for Inclusive and Sustainable Development: Kuznets, Piketty and The Great Policy Reversal. Journal of Economic Surveys, 30(4), $736-755$.

Bak, C., Bhattacharya, A., Edenhofer, O., \& Knopf, B. (2017). Toward a Comprehensive Approach to Climate Policy, Sustainable Infrastructure and Finance. Centre for International Governance Innovation Policy Brief No. 106. Centre for International Governance Innovation.

Balch, O. (2016). Indian law requires companies to give $2 \%$ of profits to charity. Is it working? Available from: https://www.theguardian.com/sustainable-business/2016/ apr/05/india-

Barnard, S. (2015). Climate finance for cities: How can international climate funds best support low-carbon and climate resilient urban development? ODI Paper 419. Overseas Development Institute.

Barrett, S. (2013). Local level climate justice? Adaptation finance and vulnerability reduction. Global Environmental Change, 23, 1819-1829.

Barrett, S. (2014). Subnational Climate Justice? Adaptation Finance Distribution and Climate Vulnerability. World Development, 58, 130-142. 
Bergman, N., Markusson, N., Connor, P., Middlemiss, L., \& Ricci, M. (2010). Bottom-up, social innovation for addressing climate change. In Sussex Energy Group Conference -ECEEE 2010, Sussex, UK.

Bird, N., Asante, F., Bawakyillenuo, S., Trujillo, N. C., Eshetu, Z., Tumushabe, G., Yanda, P., Norman, M., Tagoe, C. A., Amsalu, A., Ashiabi, N., Mushi, D., Muhumuza, T., Kateka, A., \& Siman, B. (2016). Public spending on climate change in Africa: Experiences from Ethiopia, Ghana, Tanzania and Uganda. Overseas Development Institute.

Birkmann, J., Garschagen, M., \& Setiadi, N. (2014). New challenges for adaptive urban governance in highly dynamic environments: Revisiting planning systems and tools for adaptive and strategic planning. Urban Climate, 7, 115-133.

Bokpin, G. A. (2017). Foreign direct investment and environmental sustainability in Africa: The role of institutions and governance. Research in International Business and Finance, 39, 239-247.

Boyd, E., Ensor, J., Broto, V. C., \& Juhola, S. (2014). Environmentalities of urban climate governance in Maputo, Mozambique. Global Environmental Change, 26, $140-151$.

Brechin, S. R. (2016). Climate Change Mitigation and the Collective Action Problem: Exploring Country Differences in Greenhouse Gas Contributions. Sociological Forum, 31(S1), 846-861.

Buchner, B. K., Oliver, P., Wang, X., Carswell, C., Meattle, C., \& Mazza, F. (2017). Global Landscape of Climate Finance. Climate Policy Initiative. Academic Press.

Buurman, J., \& Babovic, V. (2016). Adaptation Pathways and Real Options Analysis: An approach to deep uncertainty in climate change adaptation policies. Policy and Society, 35, 137-150.

Chirambo, D. (2017). Increasing the value of climate finance in an uncertain environment: Diaspora financial resources as a source of climate finance for SubSaharan Africa. AIMS Environmental Science, 4(6), 730-742.

Chirambo, D. (2019). Managing Conflict through Private Sector Action on the GrowthClimate-Peace Nexus: A New Microfinance Paradigm for sub-Saharan Africa. Journal of Conflict and Integration.

Chu, R., Anguelovski, I., \& Carmin, J. (2016). Inclusive approaches to urban climate adaptation planning and implementation in the Global South. Climate Policy, 16(3), 372-392.

Clark, R., Reed, J., \& Sunderland, T. (2018). Bridging funding gaps for climate and sustainable development: Pitfalls, progress and potential of private finance. Land Use Policy, 71, 335-346. 
Crick, F., Ekander, S., Fankhauser, S., \& Diop, M. (2017). How do African SMEs respond to climate risks? Evidence from Kenya and Senegal. Centre for climate change economics and policy. Working Paper 138, Centre for Climate Change Economics and Policy.

FAO (The Food and Agriculture Organisation of the United Nations). (2015). The state of food and agriculture social protection and agriculture: Breaking the cycle of rural poverty. FAO.

Field, C. B., Mortsch, L. D., Brklacich, M., Forbes, D. L., Kovacs, P., Patz, J. A., Running, S. W., \& Scott, M. J. (2007). North America. Climate Change 2007: Impacts, Adaptation and Vulnerability, Contribution of Working Group II to the Fourth Assessment Report of the Intergovernmental Panel on Climate Change (M. L. Parry, O. F. Canziani, J. P. Palutikof, P. J. van der Linden, \& C. E. Hanson, Eds.; Vol. 639). Cambridge University Press.

Ford, J. D., Berrang-Ford, L., Bunce, A., McKay, C., Irwin, M., \& Pearce, T. (2015). The status of climate change adaptation in Africa and Asia. Regional Environmental Change, 15, 801-814.

Freistein, K., \& Mahlert, B. (2016). The potential for tackling inequality in the Sustainable Development Goals. Third World Quarterly, 37(12), 2139-2155.

Gold, R., Görg, H., Hanley, A., \& Seric, A. (2017). South-South FDI: Is it really different? Review of World Economics, 153, 657-673.

Hallegatte, S., Bangalore, M., Bonzanigo, L., Fay, M., Kane, T., Narloch, U., Rozenberg, J., Treguer, D., \& Vogt-Schilb, A. (2016). Shock Waves: Managing the Impacts of Climate Change on Poverty. Climate Change and Development Series. World Bank.

Hancock, K. J. (2015). The expanding horizon of renewable energy in sub-Saharan Africa: Leading research in the social sciences. Energy Research \& Social Science, $5,1-8$.

Hood, C., Adkins, L., \& Levina, E. (2015). Overview of INDCs Submitted by 31 August 2015. Paper No. 2015(4). Climate Change Expert Group. Organisation for Economic Co-operation and Development. OECD.

Jiang, K., \& Hanaoka, T. (2017). Can we go beyond INDCs: Analysis of future mitigation possibility in China, Japan, EU and the U.S. Advances in Climate Change Research, 8(2), 117-122.

Kiunsi, R. (2013). The constraints on climate change adaptation in a city with a large development deficit: The case of Dar es Salaam. Environment and Urbanization, 25(2), 321-337. 
Kuyper, J. W., Linnér, B., \& Schroeder, H. (2018). Non-state actors in hybrid global climate governance: Justice, legitimacy, and effectiveness in a post-Paris era. Wiley Interdisciplinary Reviews: Climate Change, 9, e497.

Levin, K., Rich, D., Bonduki, Y., Comstock, M., Tirpak, D., Mcgray, H., Noble, I., Mogelgaard, K., \& Waskow, D. (2015). Designing and Preparing Intended Nationally Determined Contributions (INDCs). World Resources Institute.

Maupin, A. (2017). The SDG13 to combat climate change: An opportunity for Africa to become a trailblazer? African Geographical Review, 36(2), 131-145.

Mayrhofer, J. P., \& Gupta, J. (2016). The science and politics of co-benefits in climate policy. Environmental Science \& Policy, 57, 22-30.

Mbeva, K., Ochieng, C., Atela, J., Khaemba, W., \& Tonui, C. (2015). Intended Nationally Determined Contributions as a Means to Strengthening Africa's Engagement in International Climate Negotiations. Climate Resilient Economies Working Paper no. 001/2015. African Centre for Technology Studies (ACTS). ACTS Press, Nairobi.

Nagoda, S. (2015). New discourses but same old development approaches? Climate change adaptation policies, chronic food insecurity and development interventions in northwestern Nepal. Global Environmental Change, 35, 570-579.

NDRC (The National Development and Reform Commission). (2015). China's Policies and Actions on Climate Change. NDRC.

Nightingale, A. J. (2017). Power and politics in climate change adaptation efforts: Struggles over authority and recognition in the context of political instability. Geoforum, 84, 11-20.

Northrop, E., Biru, H., Lima, S., Bouye, M., \& Song, R. (2016). Examining the Alignment between the Intended Nationally Determined Contributions and Sustainable Development Goals. Working Paper. World Resources Institute.

Obeng-Odoom, F. (2011). The Informal Sector in Ghana under Siege. Journal of Developing Societies, 27(3\&4), 355-392.

Ojha, H. R., Ghimire, S., Pain, A., Nightingale, A., \& Dhungana, H. (2016). Policy without politics: Technocratic control of climate change adaptation policy making in Nepal. Climate Policy, 16(4), 415-433.

Pasquini, L., Cowling, R. M., \& Ziervogel, G. (2013). Facing the heat: Barriers to mainstreaming climate change adaptation in local government in the Western Cape Province, South Africa. Habitat International, 40, 225-232.

Revi, A., Satterthwaite, D. E., Aragón-Durand, F., Corfee-Morlot, J., Kiunsi, R. B. R., Pelling, M., Roberts, D. C., \& Solecki, W. (2014). Urban areas. In Climate Change 2014: Impacts, Adaptation, and Vulnerability. Part A:Global and Sectoral Aspects. Contribution of Working Group II to the Fifth Assessment Report of the Intergovernmental Panel on Climate Change (pp. 535-612). Cambridge University Press. 
Santos, N. (2003). Financing small, medium and micro enterprises in post-conflict situations Microfinance opportunities in the Democratic Republic of the Congo. OECD Discussion Paper 28728. OECD Development Centre.

Satterthwaite, D., Archer, D., Colenbrander, S., Dodman, D., Hardoy, J., \& Patel, S. (2018). Responding to climate change in cities and in their informal settlements and economies. IIED and IIED-América Latina.

Schwartz, J., Hahn, S., \& Bannon, I. (2004). The Private Sector's Role in the Provision of Infrastructure in Post-Conflict Countries: Patterns and Policy Options. PublicPrivate Infrastructure Advisory Facility.

Sireh-Jallow, A. (2017). Revenue Diversification: Non-Traditional Sources of Development Finance as Game Changers in Africa. International Journal of Economics and Finance, 9(3), 275-282.

Stringer, L. C., Dougill, A. J., Dyer, J. C., Vincent, K., Fritzsche, F., Leventon, J., Falcao, M. P., Manyakaidze, P., Syampungani, S., Powell, P., \& Kalaba, G. (2014). Advancing climate compatible development: Lessons from southern Africa. Regional Environmental Change, 14, 713-725.

Suberu, M., Mustafa, M., \& Bashir, N. (2013). Status of renewable energy consumption and developmental challenges in Sub-Sahara Africa. Renewable \& Sustainable Energy Reviews, 27, 453-463.

Tawney, L., Miller, M., \& Bazilian, M. (2015). Innovation for sustainable energy from a pro-poor perspective. Climate Policy, 15(1), 146-162.

Taylor, A., \& Peter, C. (2014). Strengthening climate resilience in African cities: A framework for working with informality. African Centre for Cities.

UN (United Nations). (2018a). Progress towards the Sustainable Development Goals: Report of the Secretary-General. E/2018/64. UN Economic and Social Council.

UN (United Nations). (2018b). The Sustainable Development Goals Report 2018. UN Department of Economic and Social Affairs.

UNEP. (2016). The Adaptation Finance Gap Report 2016. United Nations Environment Programme. UNEP.

Urban, F. (2018). China's rise: Challenging the North-South technology transfer paradigm for climate change mitigation and low carbon energy. Energy Policy, 113, $320-330$.

Urpelainen, J. (2012). Strategic problems in North-South climate finance: Creating joint gains for donors and recipients. Environmental Science \& Policy, 21, 14-23. 
van Asselt, H. (2016). The Role of Non-State Actors in Reviewing Ambition, Implementation, and Compliance under the Paris Agreement. Climate Law, 6(1-2), 91-108.

van Gevelt, T., Holzeis, C. C., Fennell, S., Heap, B., Holmes, J., Depret, M. H., Jones, B., \& Safdar, M. T. (2018). Achieving universal energy access and rural development through smart villages. Energy for Sustainable Development, 43, 139-142.

Weigel, M. (2016). China's Climate Change South-South Cooperation: Track Record and Future Direction. United Nations Development Programme in China.

Wong, S. (2016). Can climate finance contribute to gender equity in developing countries? Journal of International Development, 28(3), 428-444.

Yu, Y. (2014). Climate finance, Africa and China's role. African East-Asian Affairs, $1,36-57$. 